\title{
Performance comparison between Islamic and conventional stocks: evidence from Pakistan's equity market
}

\author{
Munazza Jabeen
}

International Institute of Islamic Economics, International Islamic University, Islamabad, Pakistan, and

Saba Kausar

Management Science, International Islamic University, Islamabad, Pakistan

\begin{abstract}
Purpose - This paper aims to examine the performance of Islamic and conventional stocks listed at the Pakistan Stock Exchange by using both parametric and non-parametric approaches. The motivation is to do risk-return analysis of Islamic stock prices and conventional stock prices.

Design/methodology/approach - It uses various measures of performance, e.g. Sharpe ratio, Treynor ratio, Jensen's alpha, beta, generalized auto-regressive conditional heteroskedasticity and stochastic dominance. Using the Karachi Meezan Index-30 (KMI-30) and the Karachi Stock Exchange Index-30 (KSE-30) as proxies for Islamic and conventional stock prices, respectively, it examines the performance of Islamic and conventional stocks. The daily data of KMI-30 and KSE-30, covering period from June 9, 2009 to June 20, 2020 are used.

Findings - The results show that the overall KMI-30 outperforms the KSE-30. The returns of the KMI-30 are greater than the KSE-30. However, the risk and volatility of the KMI-30 and KSE-30 are similar. Further, the KMI-30 has higher excess returns per unit of total risk than the KSE-30. But both indexes have similar excess returns per unit of systematic risk. Moreover, the KMI-30 returns have stochastically dominance over the KSE30 returns. These results reveal that the Islamic index performs better than the conventional index.

Practical implications - The findings provide several practical implications in financial and investment decisions making by investors, managers and policymakers such as strategies for asset allocation and investment. Further, in risk management, it provides guidance for allocating portfolios and managing risk. The investment in Islamic stocks may mitigate potential risk within asset portfolios.

Originality/value - This research is unique in its approach to the analysis of the performance comparison of conventional and Islamic stock by using comprehensive parametric and non-parametric estimation techniques. Such research has not been undertaken in the Pakistan's equity market since.
\end{abstract}

Keywords Conventional index, Islamic index, GARCH, Performance measures, Stochastic dominance (SD), Stock performance

Paper type Research paper

\section{Introduction}

Islamic equity markets have seen significant growth and progress during the past decade. The main reason for this growth and progress is that there is an increasing number of

(C) Munazza Jabeen and Saba Kausar. Published in ISRA International Journal of Islamic Finance. Published by Emerald Publishing Limited. This article is published under the Creative Commons Attribution (CCBY 4.0) licence. Anyone may reproduce, distribute, translate and create derivative works of this article (for both commercial and non-commercial purposes), subject to full attribution to the original publication and authors. The full terms of this licence maybe seen at http://creativecommons. org/licences/by/4.0/legalcode.

This article is based on an earlier version of the paper titled "a comparison between Islamic and conventional stock prices performance: evidence from Pakistan's equity market," which was presented at the 6th International Conference on Islam and Liberty, Islamabad held on November 14-15, 2018.

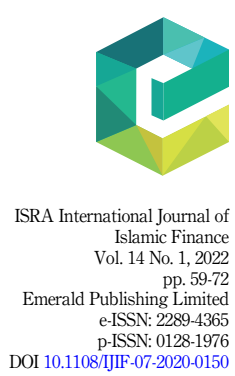

Received 19 July 2020

Revised 4 October 2020 10 June 2021

15 September 2021

5 October 2021

Accepted 25 October 2021

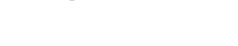


IJIF

14,1

60

investors seeking investment in Sharíah-compliant financial instruments. The Sharíah (Islamic law) principles relating to the prohibition of riba (interest), gharar (excessive uncertainty), maysir (speculation) and engagement in unethical financial transactions form the foundation of Islamic equity markets (Shanmugam and Zahari, 2009). Under this framework, investments in equity capital are consistent with ethically oriented and socially responsible investments. These characteristics distinguish Islamic equity markets from their conventional counterparts.

Compared to studies on conventional stock markets, empirical studies on Shariah-compliant stocks are still scarce, despite the growth of the Islamic equity market. Empirical research on stock markets tends to focus on risk-return analysis and performance in diverse markets to investigate key features of stock prices (Rana and Akhter, 2015; Bahloul et al., 2017; Bayram and Othman, 2019; Trabelsi et al., 2020). The majority of studies evaluate the performance comparison of different stock indexes by using parametric approaches such as the capital asset pricing model (CAPM) statistics and non-parametric approaches such as generalized autoregressive conditional heteroskedasticity $(\mathrm{GARCH})$ and stochastic dominance (SD) (Al-Khazali et al., 2014; Jawadi et al., 2014; Rana and Akhter, 2015; Shah et al., 2017; Abduh, 2020).

The parametric approach such as CAPM is based on the assumption of normality. It relies only on the first two moments of the returns distribution to test the performance of stocks. It depends on quadratic utility functions and is, therefore, not adequate for non-normal distributions or non-quadratic investors' utility functions. The non-parametric approaches such as GARCH and SD incorporate the non-normality in returns distribution and could lead to different conclusions compared to the parametric approach. The SD approach does not require an explicit specification of utility of the investor or constraints on the probability distribution function. Instead, it is based on "general assumptions about non-satiety and risk preferences of investors" and takes the cumulative distribution of returns into account, not just the first two moments (Kuosmanen, 2001, p. 1,394).

The studies on the performance comparison of Islamic and conventional stocks show mixed results. Some studies conclude that, based on both return and risk performance, Islamic stocks perform better than conventional stocks (Al-Zoubi and Maghyereh, 2007; Al-Khazali et al., 2014; Jawadi et al., 2014; Abduh, 2020). Some other studies report that Islamic stocks underperform conventional stocks (Hayat and Kraeussl, 2011; Rana and Akhter, 2015). However, Albaity and Ahmad (2008), Abbes (2012), Bayram and Othman (2019), and Trabelsi et al. (2020) found that no substantial difference exists between Islamic and traditional stocks' performance. The main reason behind these mixed results is that these studies use "either parametric (CAPM statistics) or non-parametric (GARCH, SD) approaches to compare the performance of conventional and Islamic stocks" (Jabeen et al., 2018, p. 2).

Keeping in view the different techniques being used in the literature for comparison of Islamic and conventional stocks and their underlying assumptions about the utility function, nature of distribution and other aspects, this paper refers to a wider range of approaches to compare the performance of Islamic and conventional stocks to get more robust results.

For this purpose, this paper aims to examine the performance of Islamic and conventional stocks listed on the Pakistan Stock Exchange (PSX) by using both parametric and nonparametric approaches to compare the results. The motivation is to perform risk-return analysis of Islamic and conventional stocks by considering higher moments of stock prices and the characteristics of their distribution to investigate the following research question: do Islamic stocks perform better than conventional stocks based on risk-return analysis?

This paper empirically studies the performance comparison of the stocks by using different non-risk- and risk-adjusted performance measures. The Karachi Meezan Index-30 (KMI-30) and the Karachi Stock Exchange Index-30 (KSE-30) are used as proxies for Islamic stock prices and conventional stock prices, respectively. To evaluate the risk-return performance of the KMI-30 and KSE-30, various performance measures such as Treynor 
ratio, Sharpe ratio, beta, GARCH, Jensen's alpha and the SD approach are used by considering data ranging from June 9, 2009 to June 20, 2020.

This paper will contribute to the Islamic finance literature by analyzing the combination of both parametric and non-parametric approaches to test the performance comparison of Islamic and conventional stocks with respect to returns and risks in the context of Pakistan. The findings of this paper would be useful for individuals, investors, managers and policymakers in making investment decisions and devising investment strategies.

The layout of the paper is as follows: the next section reviews the relevant literature; it is followed by a description of the data and methods used in the research; the next section provides the empirical findings and a discussion thereof; and the last section concludes the study.

\section{Literature review}

Research on the performance comparison of Islamic and conventional stocks finds mixed results in the literature. Studies focus on risk-return analysis and performance of stocks in different markets to investigate key features of stocks. They analyze performance comparison based on both return and risk performance measures by using parametric methodologies and non-parametric approaches.

Several studies compare return and risk performance by using the CAPM and CAPM statistics. On the one hand, some studies find that the Islamic index outperforms the conventional index. For example, comparing the return performance of Islamic and conventional stock indexes, Hakim and Rashidian (2004) find that the Dow Jones Islamic Market Index (DJIM) performs relatively well in comparison to the Dow Jones Global Index (DJ Global) and underperforms in comparison to Dow Jones Sustainability World Index (DJSI World). Also, Hussein (2004) concludes that FTSE-Global Islamic Index performs better than FTSE All-World Index in terms of returns. Similarly, Albaity and Ahmad (2008) show that Kuala Lumpur Composite Index (KLCI) significantly outperforms Kuala Lumpur Shariah Index (KLSI). Alam and Ansari (2020) also find that the returns of Islamic stock indexes provide superior performance to conventional stock indexes in India.

On the other hand, Girard and Hassan (2005) find no difference in returns between Islamic and non-Islamic indexes while examining the comparative performance of DJIM with its nonIslamic counterparts. Ata and Buğan (2015) also conclude that there is no significant difference between the return performance of Islamic and conventional Dow Jones Turkey (DJTR) and Morgan Stanley indexes (MSCI) for Turkey. Similarly, while comparing the performance of KATILIM 50 and BIST 100 indexes in Turkey's stock market, Bayram and Othman (2019) find no significant difference between the performance of the KATILIM 50 index and BIST 100 index. The findings of Abbes (2012), Trabelsi et al. (2020) and Aarif et al. (2021) support the previous studies that there is no substantial difference in return performance between Islamic and conventional stocks in developed and emerging stock markets. In another study, Hussein and Omran (2005) find that DJIM outperforms its counterpart indexes over the bull period and underperforms its counterpart indexes over the bear period. But, Liu and Chang (2021) discover that Islamic stock markets exhibit dominance over conventional stock markets in bearish periods.

Analyzing the performance of relative risk of DJIM and DJ Global, Al-Zoubi and Maghyereh (2007) conclude that the Islamic index outperforms the Global index on the basis of risk. DJIM has lower risk than DJ Global because of the profit-and-loss-sharing principle. On the other hand, Rana and Akhter (2015) show that KMI-30 underperforms KSE-100 on the basis of risk. The reasons for the low performance of the Islamic stocks are high monitoring costs and smaller investment magnitude.

Analyzing risk and return through CAPM-GARCH, Abu-Alkheil et al. (2020) compare the performance of Islamic and conventional stock indexes of DJ Global, MSCI, FTSE, Standard \&
Islamic and conventional stocks 
IJIF

14,1

62

Poor's (S\&P) and Jakarta Islamic Index (JII). Their findings reveal that Islamic stock indexes are less responsive to average market changes than conventional stock indexes having similar risk. The Islamic stock indexes underperform conventional stock indexes. However, through CAPM statistics, Suryadi et al. (2021) find that the JII has larger excess returns while having the same risk as compared to its conventional counterparts in Indonesia. Asutay et al. (2021), using the CAPM-EGARCH model, undertake performance comparison between Islamic and conventional indices based on four main markets: worldwide, the USA, Europe and AsiaPacific. Their finding shows that Islamic indexes yield higher average returns and lower risks in comparison to conventional indexes.

Through the CAPM-GARCH model, Jawadi et al. (2014) conclude that before the global financial crisis (GFC) of 2008, conventional indexes outperform Islamic indexes, whereas Islamic indexes outperform conventional indexes after the GFC of 2008. Asutay et al. (2021), using the CAPM-EGARCH model, find that Islamic indexes outperformed conventional indexes during the GFC period and the post-crisis phase, particularly in the European and Asia-Pacific markets. Using the SD methodology, Al-Khazali et al. (2014) compare conventional Dow Jones indexes to Islamic Dow Jones indexes. They discover that all conventional stock indexes stochastically dominate Islamic stock indexes. In a study, Abduh (2020) analyzes the effect of the GFC on the performance of stocks in Malaysia and concludes that the performance of Islamic stocks is high, and they are less volatile in the time of financial crises as compared to conventional stocks. Also, Liu and Chang (2021) find that Islamic stock markets have emerged as a superior investment alternative since the GFC.

Comparing the performance of conventional and Islamic foreign portfolios, Hendranastiti and Asutay (2016) compare the portfolio performance of Shariah portfolios and the counterpart portfolios in the UK. They conclude that the Shari ah portfolios have higher risk than the counterpart portfolios. Abu-Alkheil et al. (2017), Bahloul et al. (2017) and Abu-Alkheil et al. (2017) conclude that Islamic indexes are better hedging investments and better alternative investments in the time of financial downturns. Hence, they are a good substitute for conventional stocks. Similarly, González et al. (2019) find that Islamic sector portfolios outperform conventional sector portfolios on all performance measures. Empirical results from Ben Rejeb and Arfaoui (2019), on the basis of informational efficiency and risk, indicate that Islamic stock indexes are more efficient and volatile than their conventional stock indexes. Hoque et al. (2020) compare the performance of Islamic and conventional stock portfolios in Malaysia. They find that, according to CAPM statistics, Islamic stock portfolios generate a higher return while having a lower systematic risk than conventional stock portfolios. According to the SD approach, Islamic stock portfolios outperform conventional stock portfolios in terms of portfolio returns. Overall, the risk-sharing Islamic stock portfolios outperform the risk-bearing conventional stock portfolios in terms of returns.

The preceding literature shows different conclusions on the performance comparison of conventional and Islamic stocks. Several researchers have found that Islamic stocks outperform conventional stocks. However, some research show that conventional stocks outperform their counterparts. This finding varies from developed countries to emerging counties, before and after the GFC of 2008, and from parametric and non-parametric methodologies. However, there is a need to study the performance comparison of conventional and Islamic stocks in terms of both returns and risk by employing a combination of both non-parametric and parametric approaches.

\section{Data}

This paper uses the price data of KMI-30 and KSE-30 as proxies for Islamic stock prices and conventional stock prices, respectively. The market index is the KSE-100. It also uses the T-bill rate of six months for measuring the risk-free rate. The daily stock price data from the 
period June 9, 2009 to June 30, 2020, for each index and the six-month T-bills rate are used for the analysis. The KMI-30 was launched in 2009, while the KSE-30 was launched in 2006; therefore, for the performance comparison, their data from June 2009 is taken for analysis. The sources of data are the PSX and International Financial Statistics (IFS).

\section{Karachi Meezan Index-30 and the Karachi Stock Exchange Index-30}

The KMI-30 is a Shariah-compliant stock index comprising the top 30 qualifying companies listed on the PSX, while the KSE-30 is a conventional stock index of 30 companies listed on the PSX. Both indexes are generated using the free-float market capitalization technique. According to the PSX, the KMI-30 level reflects the free-float market value of 30 Shariahcompliant companies' shares over the base period, while the KSE-30 level reflects the freefloat market value of 30 conventional companies' shares over the base period.

\section{Methodology}

For the performance comparison between Islamic and conventional indexes in Pakistan's equity market, this paper examines the return and risk characteristics of each index. It also investigates the risk-adjusted performance of each index.

The autoregressive moving average (ARMA) $(p, q) \operatorname{GARCH}(p, q)$ model is used to compare the return and volatility performance of Islamic and conventional stock indexes. The ARMA $(p, q) \mathrm{GARCH}(p, q)$ model is specified as follows:

$$
\begin{gathered}
R_{i, t}=c_{i}+\sum_{l=1}^{p} \delta_{i, l} R_{i, t-l}+\sum_{m=1}^{q} \boldsymbol{\varphi}_{i, m} \varepsilon_{i, t-m}+\varepsilon_{i, t} \\
h_{i, t}=\omega_{i}+\sum_{j=1}^{p} \theta_{i, j} \varepsilon_{t-\mathrm{j}}^{2}+\sum_{k=1}^{q} \varnothing_{i, k} h_{t-k}
\end{gathered}
$$

where $R_{i, t}$ is the return of an index $i$, and $h_{i, t}$ is a conditional variance of the return of an index $i$, which denotes stock price volatility. Moreover, $\omega_{i}>0, \theta_{i, j} \geq 0$ and $\varnothing_{i, j} \geq 0$. For the estimation of the GARCH model, the maximum likelihood (MLE) method is used.

In addition to examining the first two moments, this paper also examines third-order moments of the index series. For this, the SD non-parametric test statistic is used to check the dominance of any pair of the returns series. The three SD approach rules, named first-order SD (FSD), second-order SD (SSD) and third-order SD (TSD), are based on a utility function, which is given by Hadar and Russell (1969). To check the SD, the Kolmogorov-Smirnov (KS) type test by Barrett and Donald (2003) is used. The description of the KS type test is as follows:

Let $\left\{L_{i}\right\}$, where $i=1,2, \ldots \ldots, N$ is a random sample drawn from a population with cumulative distribution function $(\mathrm{CDF})$, be denoted by $F_{L}(a)$ of KSE-30 returns, and the notation $D_{L}^{s}(a)$ is the function that integrates $F_{L}(a)$ to $s$ th SD orders, where $a>0$ for all cases. The following rules explain the three orders of SD:

$$
\begin{gathered}
D_{L}^{1}(a)=F_{L}(a) \text { For FSD } \\
D_{L}^{2}(a)=\int_{0}^{a} F_{L}(u) \mathrm{du}=\int_{0}^{a} D_{L}^{1}(u) \mathrm{du} \text { For SSD } \\
D_{L}^{3}(a)=\iint_{0}^{a} F_{L}(v) \mathrm{d} v \mathrm{du}=\int_{0}^{a} D_{\mathrm{L}}^{2}(u) \mathrm{du} \text { For TSD }
\end{gathered}
$$

Islamic and conventional stocks$$
\begin{aligned}
& \text { period June 9, } 2009 \text { to June } 30,2020 \text {, for each index and the six-month T-bills rate are used for } \\
& \text { the analysis. The KMI-30 was launched in } 2009 \text {, while the KSE-30 was launched in } 2006 \text {; } \\
& \text { therefore, for the performance comparison, their data from June } 2009 \text { is taken for analysis. } \\
& \text { The sources of data are the PSX and International Financial Statistics (IFS). } \\
& \text { Karachi Meezan Index-30 and the Karachi Stock Exchange Index-30 } \\
& \text { The KMI-30 is a Shariah-compliant stock index comprising the top } 30 \text { qualifying companies } \\
& \text { listed on the PSX, while the KSE-30 is a conventional stock index of } 30 \text { companies listed on the - } \\
& \text { PSX. Both indexes are generated using the free-float market capitalization technique. } \\
& \text { According to the PSX, the KMI-30 level reflects the free-float market value of } 30 \text { Sharía- } \\
& \text { compliant companies' shares over the base period, while the KSE-30 level reflects the free- } \\
& \text { float market value of } 30 \text { conventional companies' shares over the base period. }
\end{aligned}
$$ 
IJIF

14,1

\section{4}

In the same way, suppose $\left\{M_{i}\right\}, i=1,2, \ldots, N$, is a random sample drawn from a population with $\mathrm{CDF}$ denoted by $F_{M}(a)$ of KMI-30 returns and the notation $D_{M}^{s}(a)$ is the function that integrates $F_{M}(a)$ to $s$ th SD orders.

The null hypothesis states that the returns series (KSE-30) named " $L$ " stochastically dominates over the return series of KMI-30 returns named " $M$ ". The alternative hypothesis, on the other hand, suggests that distribution M stochastically outperforms distribution $L$. The null and alternative hypotheses for testing the SD order of returns " $L$ " over asset " $M$ " are as follows:

$$
\begin{array}{ll}
H_{0}^{s}: D_{L}^{s}(a) \leq D_{M}^{s}(a) & \text { for all } a \text { (stock returns) } \\
H_{1}^{s}: D_{L}^{s}(a) \leq D_{M}^{s}(a) & \text { for all } a \text { (stock returns) }
\end{array}
$$

The following KS test by Barrett and Donald (2003) is used to test the null hypothesis $\left(H_{0}^{s}\right)$ :

$$
K_{s}=\left(\frac{N^{2}}{2 N}\right)^{1 / 2} \frac{\sup }{a} \cdot\left[D_{L}^{-s}(a)-D_{M}^{-s}(a)\right]
$$

This test is used for SD of the second $(s=2)$ or higher orders $(s>2)$. The simulation approach is used to derive $p$-values for the underlying null hypothesis to determine the value of the suprema of test statistics, $K_{s}$.

The risk-adjusted returns of Islamic and conventional stock indexes are computed from CAPM statistics such as Sharpe ratio, Treynor ratio (TR) and Jensen's alpha for performance comparison. The daily returns series of an index $i, R_{i, t}$ is constructed as logarithmic first difference of closing prices over the period $[t, t+1]$. The standard deviation of returns of an index $i, \sigma\left(R_{i, t}\right)$ is used for the total risk for returns of an index $i$. The returns and standard deviation of the returns and CAPM statistics are commonly employed to evaluate stock performance.

The Sharpe ratio, which measures the average risk premium per unit of total risk, is computed as follows:

$$
\mathrm{SR}=\frac{R_{i, t}-R_{f, t}}{\sigma\left(R_{i, t}\right)}
$$

where $R_{i, t}$ is the return of an index $i, R_{f, t}$ is the risk-free return and $\sigma\left(R_{i, t}\right)$ is the standard deviation of return of an index $i$.

The Sharpe ratio indicates that an index with a greater sharp ratio (SR) has larger excess returns with the same risk. As a result, its financial performance has improved. In addition, if the SR is positive (negative), it signifies that an index $i$ outperforms (underperforms) risk-free assets.

The Treynor ratio, which measures the average risk premium per unit of systematic risk, is computed as follows:

$$
\mathrm{TR}=\frac{R_{i, t}-R_{f, t}}{\beta_{i}}, \beta_{i}=\frac{\operatorname{Cov}\left(R_{i, t}, R_{M, t}\right)}{\sigma_{M, t}^{2}}
$$

where $\beta_{i}$ is the market beta of return of an index $i$. It is computed as the ratio of the covariance between the return $R_{i, t}$ and the market return $R_{M, t}$ to the variance of the market return $\sigma_{M, t}^{2}$.

The Treynor ratio illustrates that an index with a greater TR has larger excess returns with the same systematic risk. As a result, its financial performance has improved. 
Jensen's alpha measures the performance of risk-adjusted returns and is computed from the CAPM as follows:

$$
R_{i, t}-R_{f, t}=\alpha+\beta\left(R_{M, t}-R_{f, t}\right)
$$

where $\alpha$ is the Jensen alpha, $R_{i, t}-R_{f, t}$ is the excess return of an index $i$ and $R_{M, t}-R_{f, t}$ is the excess market return toward risk-free return.

\section{Empirical findings}

Non-risk-adjusted returns characteristics

The plot of daily prices of the KMI-30 and KSE-30 over the sample period is given in Figure 1. It shows that the prices of the KMI-30 are larger than the prices of the KSE-30 in Pakistan's equity market. Abbes (2012) reports similar findings for emerging markets.

The plots of daily returns of the KMI-30 and KSE-30 over the sample period are given in Figure 2. The returns show no discernible trend. The figure shows that index returns quickly return to their mean. It also shows that index returns' variances fluctuate over time and volatility tends to cluster.

Table 1 presents descriptive statistics for KMI-30 and KSE-30 returns. The KMI-30 and KSE-30 returns are positive on average. The daily mean return of KMI-30 is $0.061 \%$ and $0.025 \%$ for KSE-30. Thus, the KMI-30 has higher returns than the KSE-30. It implies Islamic stocks have higher returns as compared to conventional stocks. The standard deviation, which measures unconditional volatility, shows variations across returns of KMI-30 and KSE-30. As a measure of total risk, the values of standard deviation also show KMI-30 and KSE-30 having similar risks, about 1.2\%. It implies that Islamic and conventional stocks have similar risk. Both KMI-30 and KSE-30 are negatively skewed because the mean is lower than the median and mode. Both KMI-30 and KSE-30 series show excess kurtosis, indicating heavy-tailed and leptokurtic distribution of the daily stock returns. Both the KMI-30 and

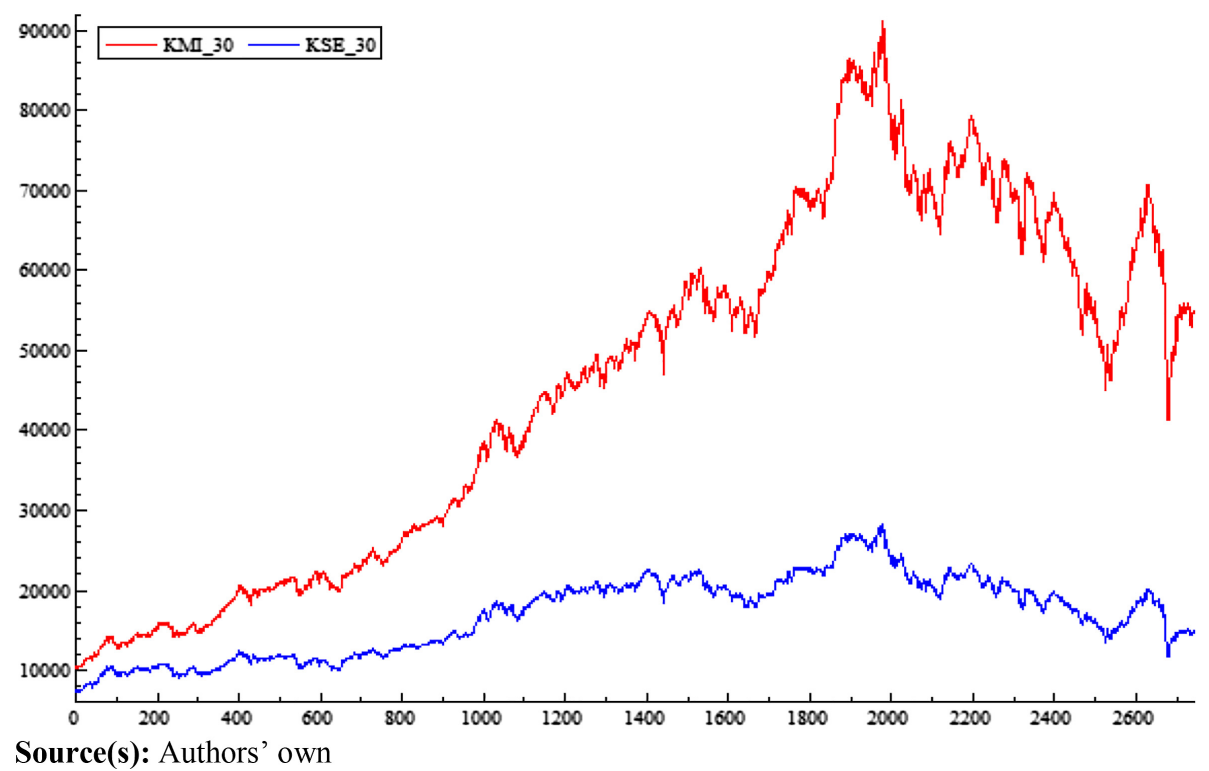

Figure 1. Daily prices of KSE-30 and KMI-30
Islamic and conventional stocks 


\section{IJIF \\ 14,1}

\section{6}

Figure 2.

Daily returns of KSE30 and KMI-30
Table 1.

Descriptive statistics and diagnostic checks of daily returns of KMI30 and KSE-30
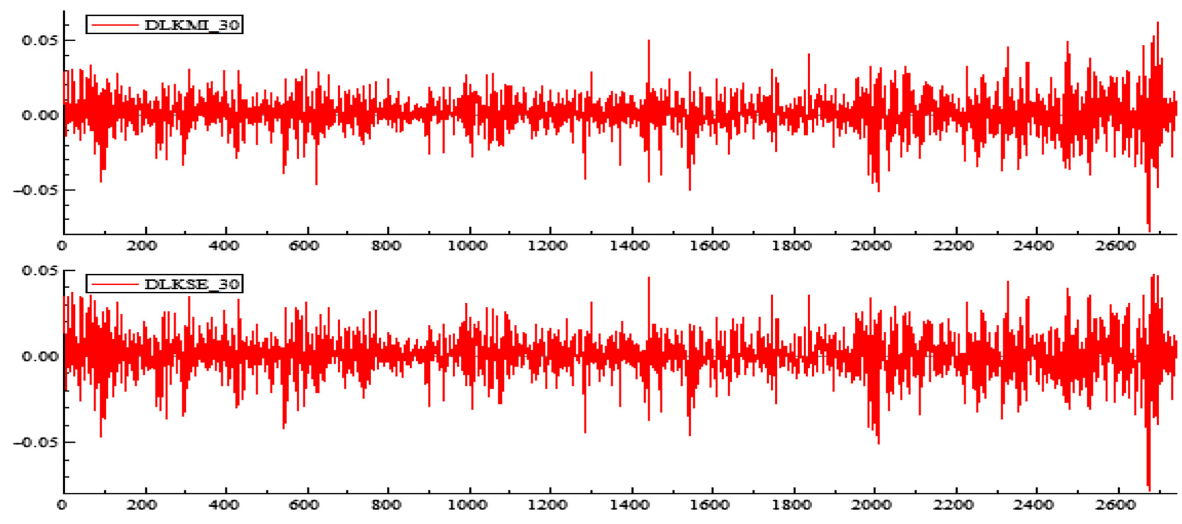

Source(s): Authors' own

Daily returns

$\begin{array}{lcc} & \text { KMI-30 } & \text { KSE-30 } \\ \text { Mean } & 0.00061 & 0.00025 \\ \text { Standard deviation } & 0.01190 & 0.01179 \\ \text { Skewness } & -0.40542^{* * *} & -0.41001^{* *} \\ \text { Excess kurtosis } & 4.0990^{* *} & 3.6839^{* *} \\ \text { Jarque-Bera } & 1994.0^{* *} & 1626.8^{* *} \\ \text { ADF test statistic (with intercept) } & -29.5448^{* *}(2) & -28.9141^{* *}(2) \\ \text { LM-ARCH 1-2 } & 175.69^{* *}(0.0000) & 174.04^{* *}(0.0000) \\ \text { LM-ARCH 1-5 } & 109.32^{* *}(0.0000) & 113.85^{* *}(0.0000) \\ \text { LM-ARCH 1-10 } & 65.358^{* *}(0.0000) & 67.357^{* *}(0.0000) \\ \text { LB-Q(10) } & 37.9867^{* *}(0.0000) & 50.1622^{* *}(0.0000) \\ \text { LB-Q(10) } & 1443.61^{* *}(0.0000) & 1395.83^{* *}(0.0000)\end{array}$

Note(s): $p$-values are in parentheses, $* *$ indicates significance at $1 \%$

Source(s): Authors' own

KSE-30 reveal non-normality in distributions, as indicated by the significant Jarque-Bera test statistic. Using the augmented Dickey-Fuller (ADF) test, KMI-30 and KSE-30 show stationarity in the first difference form. The Ljung-Box-Pierce $Q$-statistic and $Q^{2}$-statistic at lags 10 indicate the presence of serial correlation in residuals and squared residuals, and Lagrange multiplier (LM) test statistic at lags 1 to 10 shows evidence of ARCH effect.

The descriptive analysis shows mean reverting, stationarity, non-normality and volatility clustering characteristics of each index return. This finding is consistent with the studies of Jawadi et al. (2014), Rana and Akhter (2015) and Abu-Alkheil et al. (2020). This descriptive analysis exhibits stocks returns are positive and have similar risk. The stock returns have non-normal distribution. The past shocks to returns affect the current period returns.

\section{Volatility characteristics}

For the KMI-30 and KSE-30 returns, Table 2 displays the estimated ARMA (1,0)-GARCH $(1,1)$ $(1,1)$ model. The conditional mean equation demonstrates that both the KMI-30 and KSE-30 have positive average daily returns. However, the KMI-30 has larger returns than the KSE-30. This finding shows better performance of Islamic stocks in terms of returns. The ARCH and GARCH coefficients are significant, according to the estimated parameters of GARCH $(1,1)$ 
$\mathrm{IJIF}$

14,1
The plots of the daily volatility of KMI-30 and KSE-30 series show that the volatility of KMI-30 and KSE-30 are similar. This implies volatility patterns of both the Islamic and conventional indexes are similar.

This risk and return analysis shows positive and volatile returns produced in the equity market in Pakistan. High volatility persistence exists in stock returns.

\section{Stochastic dominance approach}

Figure 3 shows that the CDF of KMI-30 returns is on the right side of the CDF of KSE-30 returns. This means that the KMI-30 returns outperform its counterpart KSE-30 returns in terms of SD.

Table 4 displays the results of the SD test using the KS test. The $p$-values of the KS test of null hypotheses are also shown in the table. The first column of the table shows the SD orders, then the second and third columns present the $p$-values of the KS test. All three SD orders' KS $p$-values are more than any acceptable significance level. This implies that the KMI-30 returns outperform the KSE-30 returns in all three SD orders. By contrast, the $p$-values under the heading of KSE-30 returns against the KMI-30 returns show that KSE-30 returns do not perform better at any SD order. These findings contradict those of Al-Khazali et al. (2014), who found that conventional equities have a stochastically superior return compared to Islamic stocks.

\section{Risk-adjusted returns characteristics}

Table 5 reports different performance measures of KMI-30 and KSE-30 by using CAPM statistics. The Sharpe ratio of KMI-30 (SR = 0.0644) is higher than KSE-30 (SR = 0.0351). The Sharpe ratio shows that the KMI-30 has higher excess returns per unit of total risk than the KSE-30. It implies KMI-30 is giving better excess returns per unit of total risk than KSE-30. Thus, financial performance of Islamic stocks is better than conventional stocks according to

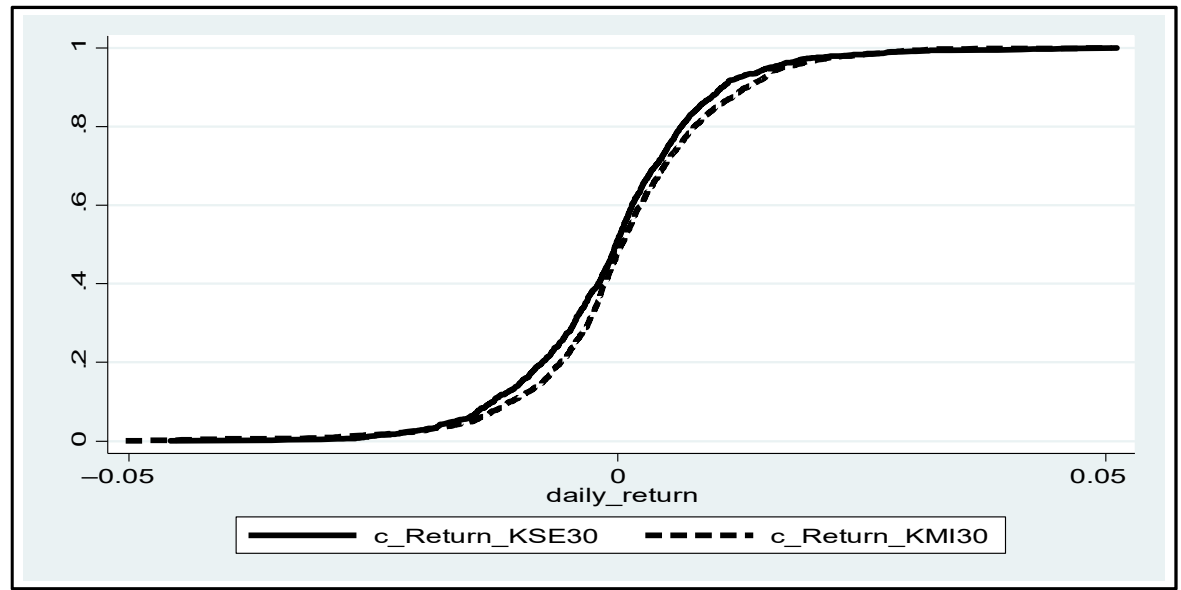

Figure 3. SD of KMI-30 returns over KSE-30 returns
Note(s): This figure shows the cumulative distribution function of KMI-30 index returns (dashed line) and KSE-30 index returns (solid line)

Source(s): Authors' own 
the Sharpe ratio. These findings are consistent with the studies of Hussein (2004), Jawadi et al. (2014), Ho et al. (2014), Alam and Ansari (2020) and Suryadi et al. (2021).

Since "rational investors are expected to diversify their portfolio in order to maintain systemic risk" (Jawadi et al., 2014, p. 18), the excess return can be evaluated according to investors' criteria. For this, the Treynor ratio is computed for both indexes. The Treynor ratio of KMI-30 $(\mathrm{TR}=0.0111)$ is similar to that of KSE-30 $(\mathrm{TR}=0.0106)$. The Treynor ratio shows both indexes have similar excess returns per unit of systematic risk. It implies KMI-30 is giving similar excess returns per unit of systematic risk than KSE-30. Thus, financial performance of Islamic stocks and conventional stocks are similar according to the Treynor ratio. These results are aligned with the findings of Abbes (2012), Jawadi et al. (2014), Bayram and Othman (2019), Trabelsi et al. (2020) and Aarif et al. (2021).

To compare the risk-adjusted performance of both indexes, Jensen's alpha is also computed from the CAPM. Jensen's alpha of KMI-30 (JA = -0.0004) is lower than that of $\mathrm{KSE}-30\left(\mathrm{JA}=-3.3 \times 10^{-5}\right)$. Jensen's alpha is negative for both indexes, which indicates that the excess market returns exceed excess returns of each index. The $\beta$ of both KMI-30 and KSE-30 is positive ( $\beta$ of KMI-30 $=1.0766$ and $\beta$ of KSE-30 $=1.1030$ ), but the KSE-30 has a higher $\beta$ than the KMI-30. It suggests that Islamic stocks have less systematic risk than conventional stocks. These results are aligned with the findings of Al-Zoubi and Maghyereh (2007) and Hoque et al. (2020).

The financial performance analysis shows that in the equity market of Pakistan, according to risk-adjusted returns, Islamic stocks are superior to conventional stocks. Also, Islamic stocks are less volatile to market than conventional stocks. This means that Islamic stocks not only provide superior returns but also carry a lower risk level.

\section{Conclusion}

The performance of Islamic and conventional stocks using their stock prices in Pakistan's equity market is compared in this paper. The paper assesses the performance of both stocks using a variety of parametric and non-parametric performance measures. The KMI-30 and KSE-30 are used as proxies for Islamic and conventional stock values, respectively.

\begin{tabular}{lcc}
\hline & KMI-30 versus KSE-30 & KSE-30 versus KMI-30 \\
\hline SD orders & & \\
SD1 & 0.938 & KS p-value \\
SD2 & 0.369 & 0.001 \\
SD3 & 0.399 & 0.000 \\
Note(s): SD of two pairs of KMI-30 and KSE-30 is displayed. KS p-values are calculated through simulation
\end{tabular}
and SD1, SD2, SD3 are three $p$-values of stochastic orders (first, second and third)

Source(s): Authors' own

Islamic and conventional stocks

Table 4. SD of KMI-30 stock returns versus KSE-30 stock returns

\begin{tabular}{lcr}
\hline Ratios & KMI-30 & KSE-30 \\
\hline Sharpe ratio (SR) & 0.0644 & 0.0351 \\
Treynor ratio (TR) & 0.0111 & 0.0106 \\
Jensen's alpha $(\alpha)$ & $-3.3 \times 10^{-5}$ & -0.0004 \\
$\beta$ & 1.0766 & 1.1030 \\
Source(s): Authors' own & & Performance measures \\
& & of KMI-30 and KSE-30 \\
\hline
\end{tabular}


IJIF

14,1

According to the findings, the overall KMI-30 outperforms the KSE-30. The KMI-30 particularly outperforms the KSE-30 in terms of returns. The KMI-30 and KSE-30, on the other hand, have similar risk and volatility levels. Furthermore, the KMI-30 has higher excess returns per unit of total risk than the KSE-30. However, both indexes have similar excess returns per unit of systematic risk. Moreover, the KMI-30 returns have SD over the KSE-30 returns. As a result, the Islamic index outperforms the conventional index. Based on the findings, it is observed that profit-and-loss sharing, comparatively lower risk, limits on short selling, and other factors contribute to Islamic stocks' superior performance over conventional stocks. These findings are especially intriguing in terms of diversification and investment opportunities for the investment in stocks. Controlling the risk associated with stocks may benefit investors.

Because of religious concerns, many people in Pakistan prefer to invest in hatälbusinesses (Islamic products) rather than Sharíah non-compliant businesses (conventional products). Therefore, from the religious and ethical perspectives, Islamic stocks are a better investment opportunity that can bring new diversification benefits to investors. Due to reduced uncertainty and speculation, returns on the Islamic stocks are superior to conventional stocks. This reveals that investors can invest in Islamic stocks as they provide higher returns and are less volatile.

The findings provide several practical implications in financial and investment decisionmaking by investors, managers and policymakers such as in the development of strategies for asset allocation and investment. Furthermore, in risk management, this study provides guidance for allocating portfolios and managing risk. The investment in Islamic stocks may mitigate potential risk within asset portfolios.

The results of this study can be used for the development of a stable, inclusive and sustainable equity market in Pakistan. The managers of the equity market should make efforts in efficient utilization of investment for better returns and risk reduction. The regulatory authorities need to take corrective actions for strengthening and stabilizing the equity market, which includes education and protection of investors, transparency and reforms. They should develop structures and standards to make the equity market efficient and stable.

\section{References}

Aarif, M.B.H., Rafiq, M.R.I. and Wahid, A.N.M. (2021), "Do Shariah indices surpass conventional indices? A study on Dhaka stock exchange", International Journal of Islamic and Middle Eastern Finance and Management, Vol. 14 No. 1, pp. 94-113.

Abbes, M.B. (2012), "Risk and return of Islamic and conventional indices", International Journal of Euro-Mediterranean Studies, Vol. 5 No. 1, pp. 1-23.

Abduh, M. (2020), "Volatility of Malaysian conventional and Islamic indices: does financial crisis matter?", Journal of Islamic Accounting and Business Research, Vol. 11 No. 1, pp. 1-11.

Abu-Alkheil, A., Khan, W.A., Parikh, B. and Mohanty, S.K. (2017), "Dynamic co-integration and portfolio diversification of Islamic and conventional indices: global evidence", The Quarterly Review of Economics and Finance, Vol. 66 No. C, pp. 212-224.

Abu-Alkheil, A., Khan, W.A. and Parikh, B. (2020), "Risk-reward trade-off and volatility performance of Islamic versus conventional stock indices: global evidence", Review of Pacific Basin Financial Markets and Policies, Vol. 23 No. 1, pp. 1-23.

Al-Khazali, O., Lean, H.H. and Samet, A. (2014), "Do Islamic stock indexes outperform conventional stock indexes? A stochastic dominance approach”, Pacific-Basin Finance Journal, Vol. 28 No. C, pp. 29-46. 
Al-Zoubi, H.A. and Maghyereh, A.I. (2007), "The relative risk performance of Islamic finance: a new guide to less risky investments", International Journal of Theoretical and Applied Finance, Vol. 10 No. 2, pp. 235-249.

Alam, M. and Ansari, V.A. (2020), "Are Islamic indices a viable investment avenue? An empirical study of Islamic and conventional indices in India", International Journal of Islamic and Middle Eastern Finance and Management, Vol. 13 No. 3, pp. 503-518.

Albaity, M. and Ahmad, R. (2008), "Performance of Syariah and composite indices: evidence from Bursa Malaysia", Asian Academy of Management Journal of Accounting and Finance, Vol. 4 No. 1, pp. 23-43.

Asutay, M., Wang, Y. and Avdukic, A. (2021), "Examining the performance of Islamic and conventional stock indices: a comparative analysis", Asia-Pacific Financial Markets, Springer. doi: 10.1007/s10690-021-09351-7.

Ata, H.A. and Buğan, M.F. (2015), "Comparison of the performances Islamic and conventional market indices and their causal relationship", International Journal of Business Management and Economic Research, Vol. 6 No. 6, pp. 455-462.

Bahloul, S., Mroua, M. and Naifar, N. (2017), "The impact of macroeconomic and conventional stock market variables on Islamic index returns under regime switching", Borsa Istanbul Review, Vol. 17 No. 1, pp. 62-74.

Barrett, G.F. and Donald, S.G. (2003), “Consistent tests for stochastic dominance”, Econometrica, Vol. 71 No. 1, pp. 71-104.

Bayram, K. and Othman, A.H.A. (2019), "Islamic versus conventional stock market indicates performance: empirical evidence from Turkey”, Iqtishadia: Jurnal Kajian Ekonomi dan Bisnis Islam, Vol. 12 No. 1, pp. 74-86.

Ben Rejeb, A. and Arfaoui, M. (2019), "Do Islamic stock indexes outperform conventional stock indexes? A state space modeling approach", European Journal of Management and Business Economics, Vol. 28 No. 3, pp. 301-322.

Girard, E. and Hassan, M.K. (2005), Faith-based Investing: The Case of Dow Jones Islamic Indices Reexamined, University of New Orleans Working Paper, New Orleans, LA.

González, M.D.L.O., Jareño, F. and El Haddouti, C. (2019), "Sector portfolio performance comparison between Islamic and conventional stock markets", Sustainability, Vol. 11 No. 17, pp. 1-23.

Hadar, J. and Russell, W.R. (1969), "Rules for ordering uncertain prospects", American Economic Review, Vol. 59 No. 1, pp. 25-34.

Hakim, S. and Rashidian, M. (2004), "How costly is investor's compliance to Sharia?", Paper Presented at the 11th Economic Research Forum Annual Conference, Sharjah, the United Arab Emirates.

Hayat, R. and Kraeussl, R. (2011), "Risk and return characteristics of Islamic equity funds", Emerging Markets Review, Vol. 12 No. 2, pp. 189-203.

Hendranastiti, N.D. and Asutay, M. (2016), "Shari'ah and SRI portfolio performance in the UK: effect of oil price decline", Islamic Economic Studies, Vol. 24 No. 2, pp. 77-103.

Ho, C.S.F., Abd Rahman, N.A., Yusuf, N.H.M. and Zamzamin, Z. (2014), "Performance of global Islamic versus conventional share indices: international evidence", Pacific-Basin Finance Journal, Vol. 28 No. C, pp. 110-121.

Hoque, A., Rakhi, S., Hassan, K. and Le, T. (2020), "The performance of stock portfolios: evidence from analysing Malaysia case and implication for open innovation”, Journal of Open Innovation: Technology, Market, and Complexity, Vol. 6 No. 4, pp. 1-13.

Hussein, K.A. (2004), "Ethical investment: empirical evidence from FTSE Islamic index", Islamic Economic Studies, Vol. 12 No. 1, pp. 1-22.

Hussein, K. and Omran, M. (2005), "Ethical investment revisited: evidence from Dow Jones Islamic indexes", The Journal of Investing, Vol. 14 No. 2, pp. 105-126. 
IJIF

14,1

Jabeen, M., Kausar, S. and Ihsan, H. (2018), "A comparison between Islamic and conventional stock prices performance: evidence from Pakistan's equity market”, Paper Presented at the 6th International Conference on Islam and Liberty, Islamabad, 14-15 November 2018.

Jawadi, F., Jawadi, N. and Louhichi, W. (2014), "Conventional and Islamic stock price performance: an empirical investigation”, International Economics, Vol. 137 No. 1, pp. 73-87.

Kuosmanen, T. (2001), Stochastic Dominance Efficiency Tests under Diversification, Helsinki School of Economics and Business Administration, Citeseer.

Liu, W.H. and Chang, J.R. (2021), "Revisiting and refining the comparison of conventional and Islamic markets' performance”, Applied Economics, Vol. 53 No. 38, pp. 1-15.

Rana, M.E. and Akhter, W. (2015), "Performance of Islamic and conventional stock indices: empirical evidence from an emerging economy", Financial Innovation, Vol. 1 No. 1, pp. 1-15.

Shah, A.D., Gull, S. and Parvez, G.S. (2017), "Comparative performance analysis of selected Islamic and conventional mutual funds of Pakistan”, Asian Journal of Islamic Finance, Vol. 2 No. 1, pp. 14-29.

Shanmugam, B. and Zahari, Z.R. (2009), A Primer on Islamic Finance, Research Foundation of CFA Institute, Charlottesville, VA.

Suryadi, S., Endri, E. and Yasid, M. (2021), "Risk and return of Islamic and conventional indices on the Indonesia stock exchange", The Journal of Asian Finance, Economics and Business, Vol. 8 No. 3, pp. 23-30.

Trabelsi, L., Bahloul, S. and Mathlouthi, F. (2020), "Performance analysis of Islamic and conventional portfolios: the emerging markets case", Borsa Istanbul Review, Vol. 20 No. 1, pp. $48-54$.

About the authors

Munazza Jabeen, $\mathrm{PhD}$, is associated with the International Institute of Islamic Economics, International Islamic University, Islamabad, Pakistan. Munazza Jabeen is the corresponding author and can be contacted at: munazza.jabeen17@gmail.com

Saba Kausar, PhD, is a scholar at the Faculty of Management Sciences, International Islamic University, Islamabad, Pakistan. She also obtained a Masters in Economics and Finance from the Institute of Islamic Economics at International Islamic University, Islamabad.

For instructions on how to order reprints of this article, please visit our website:

www.emeraldgrouppublishing.com/licensing/reprints.htm

Or contact us for further details: permissions@emeraldinsight.com 